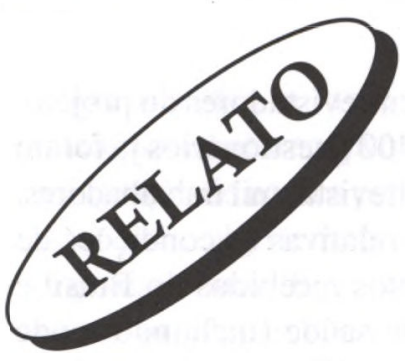

\title{
SAÚDE E SEGURANÇA NO TRABALHO DO BRASILEIRO EM MASSACHUSETTS
}

\author{
A EXPERIÊNCIA DO "PROJETO PARCERIA"
}

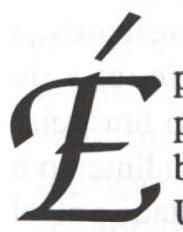

para trabalhar e juntar dinheiro a curto e médio prazo que a grande maioria dos emigrantes brasileiros deixa o Brasil com destino aos Estados Unidos. Os trabalhos disponíveis para os imigrantes são aqueles menos desejados pela população local, ou seja, os mais perigosos e com menores rendimentos. Ao mesmo tempo, saúde e segurança no trabalho não são prioridades na empreitada do imigrante, que acaba se sujeitando a situações de risco para a sua saúde que, antes da imigração, não se submeteria na maioria dos casos. Outros fatores como a situação de indocumentado, a falta de fluência em inglês, a inexperiência na nova atividade e as diferenças culturais, dentre outros, também acabam contribuindo para tornar estes trabalhadores ainda mais vulneráveis a acidentes e enfermidades ocupacionais.

O Projeto Parceria ou COBWEB em inglês (Collaboration for Better Work Environment for Brazilians) surgiu a partir de um esforço conjunto do Departamento de Ambiente do Trabalho (Work Environment Department) da Universidade de Massachusetts Lowell (UMass Lowell), do Centro do Imigrante Brasileiro (CIB) - organização nãogovernamental (ONG) criada em 1985 por trabalhadores imigrantes brasileiros em Boston - da Massachusetts Coalition for Occupational Safety and Health (MassCOSH), uma ONG do estado de Massachusetts que luta pelos direitos dos trabalhadores, e de dois centros de saúde: o Lowell Community Health Center e o Massachusetts General Chelsea Health Center.

Este artigo objetiva descrever e analisar as principais experiências deste projeto nos seus três primeiros anos.

\author{
Tiago Jansen * \\ Carlos Eduardo Siqueira ** \\ Andréa Barbosa *
}

Pesquisadores, líderes comunitários e demais interessados no estudo da emigração brasileira para os EUA encontrarão aqui exemplos de trabalhos que podem ser realizados com comunidades imigrantes. $\mathrm{O}$ foco do Projeto Parceria é saúde e segurança no trabalho, mas nossas experiências podem ser transplantadas para outras temáticas. Em cada parte do artigo descreveremos as atividades realizadas e faremos comentários sobre dificuldades e/ou sucessos dos métodos empregados.

O Projeto Parceria tem trabalhado nos últimos três anos junto à comunidade de trabalhadores imigrantes brasileiros de Massachusetts para promover melhorias nas condições de saúde e segurança no trabalho dos brasileiros que trabalham neste estado, em particular no Leste do estado. $O$ Projeto Parceria é financiado pelo NIEHS (Instituto Nacional de Ciências de Saúde Ambiental), órgão do governo americano que tem custeado outros projetos semelhantes com o intuito de buscar justiça ambiental para populações menos favorecidas dentro dos Estados Unidos. Trata-se de projeto de pesquisa com participação comunitária, que tem os seguintes objetivos:

a) Coletar dados sobre trabalhadores imigrantes brasileiros, em particular dados demográficos, sobre riscos no trabalho, relacionados com a imigração brasileira, e a experiência dos brasileiros como imigrantes nos Estados Unidos;

b) Identificar riscos no trabalho de brasileiros que trabalham em limpeza de casas (housecleaners) e negócios (janitors), na construção civil (pintores, carpinteiros, telhadores, "quebragalhos", e diaristas), jardinagem, e em restaurantes e estabelecimentos que vendem comida (como na franquia 
americana Dunkin Donuts, onde muitos brasileiros trabalham como balconistas);

c) Elaborar currículo apropriado culturalmente para o nível de educação e alfabetização dos trabalhadores brasileiros, a fimde disseminar informação sobre riscos no trabalho;

d) Recrutar e treinar uma equipe de capacitadores em técnicas de ensino de adultos para que estes treinem trabalhadores brasileiros em questões básicas de saúde e segurança no trabalho dos setores mencionados acima;

e) Elaborar estratégias de pesquisa e políticas para minimizar riscos à saúde ocupacional, juntamente com exposições ocupacionais de trabalhadores imigrantes brasileiros em trabalhos de limpeza (ex: substituição de produtos químicos tóxicos), construção civil, jardinagem e serviços de alimentação.

\section{PESQUISA}

O Projeto Parceria tem coletado dados quantitativos e qualitativos para ampliar o conhecimento sobre questões específicas relativas à saúde ocupacional do trabalhador imigrante brasileiro. A saúde do trabalhador imigrante brasileiro nos Estados Unidos é um assunto que ainda não foi abordado de forma profunda por nenhum trabalho científico de conhecimento dos autores, apesar de, como descrito acima, o trabalho ser central na vida do imigrante.

Inicialmente foram realizadas "conversas culturais," (Fawcett, 1996) uma técnica semelhante a "grupos focais," porém com formato menos rígido, para identificar os temas geradores no dia-a-dia dos trabalhadores imigrantes brasileiros. Foram realizadas "conversas culturais" com 6 grupos distintos, com em média 10 participantes em cada. Os grupos foram divididos por profissão: housecleaners, pintores, trabalhadores de restaurantes e cadeias de fast-food e jardineiros. Os dois grupos restantes foram compostos por brasileiros donos de pequenas companhias de construção residencial e jovens estudantes de "high school." As transcrições das conversas culturais foram analisadas no software Nvivo. ${ }^{(8)}$

Este método de coleta de informações se mostrou acertado para entrevistar grupos de brasileiros, porque permitiu que cada conversa tomasse a direção que os trabalhadores consideraram mais importante e facilitou o diálogo livre e aberto entre os participantes. Foi surpreendente a qualidade e a quantidade de informações coletadas através desta atividade, que facilitou sobremaneira a priorização das atividades do projeto e a elaboração do questionário formulado para a parte quantitativa da pesquisa. Estas informações inicias acabaram por moldar o direcionamento de todo o projeto.

O próximo passo foi a realização de uma pesquisa quantitativa, em desenvolvimento neste momento, através de questionário administrado por entrevistadores do projeto. Até o presente momento cerca de 400 questionários já foram administrados. Nosso objetivo é entrevistar mil trabalhadores. O questionário contém perguntas relativas às condições de emprego e de trabalho, treinamentos recebidos no Brasil e nos Estados Unidos, condições de saúde (incluindo saúde ocupacional), características demográficas e fatores sócioeconômicos.

Esta pesquisa nos possibilitará ampliar o atual conhecimento sobre a realidade vivenciada no trabalho pelos brasileiros imigrantes do estado de Massachusetts, contribuindo principalmente com informações relativas à saúde e segurança no trabalho.

Porém, os pesquisadores do Projeto Parceria não consideram correto dissociar o trabalho dos demais fatores determinantes da vida do imigrante. É necessário compreender a fundo a vida cotidiana do imigrante, que influencia a vida laboral, e vice-versa. Para tanto, além de contar com as experiências vivenciadas nos treinamentos e nos contatos permanentes com trabalhadores brasileiros, a equipe do projeto tem levantado uma variedade de informações complementares sobre a população brasileira residente em Massachusetts, como perfil de atendimento à saúde, demográficas, distribuição geográfica no estado e nível sócio-econômico.

Em parceria com o consulado brasileiro em Boston coletamos fichas de cadastro para retirada de passaportes do ano de 2003 (um total de 8623 fichas). O projeto criou um banco de dados com informações sobre idade, gênero, estado civil, ocupação, naturalidade, e cidade e estado de residência nos EUA. Não foram recolhidas informações pessoais. $\mathrm{Da}$ mesma forma, coletamos dados de duas instituições parceiras do projeto: o Centro do Imigrante Brasileiro e o Lowell Community Health Center. No momento estamos trabalhando com dois centros comunitários de apoio à comunidade, um em Allston e outro em Framingham. Nestes, o projeto contribuiu com capacitação técnica para a criação de banco de dados que inclui as fichas de cadastro de assistência a brasileiros que estas instituições já possuíam. No futuro próximo o projeto irá reunir e analisar este conjunto de dados demográficos, o que permitirá traçar um perfil quantitativo e qualitativo mais fidedigno da população imigrante brasileira em Massachusetts.

\section{TREINAMENTO}

O Projeto Parceria pretende aumentar o nível de conhecimento da comunidade brasileira em Massachusetts sobre a saúde do trabalhador. É importante que os imigrantes, recém-chegados ou não, compreendam os riscos a que estão expostos e incorporem o assunto saúde e segurança no 
trabalho na sua conversa do dia-a-dia, e que este assunto faça parte do arsenal de conhecimentos da sua rede de relações sociais (amigos, família, colegas de trabalho, etc).

O primeiro grupo ocupacional escolhido para ser treinado foi o das housecleaners, devido não só a alta prevalência deste trabalho entre as mulheres brasileiras vivendo no estado (Fleischer, 2002), como também aos conhecidos riscos que este trabalho possui: riscos ergonômicos causados por posições incômodas e movimentos repetitivos, exposição a produtos tóxicos e longas jornadas de trabalho.

Inicialmente, este treinamento utilizaria o sistema de peerleaders (ou multiplicadores), em que um pequeno grupo de housecleaners receberia treinamentos com certa profundidade e passaria a ser multiplicador da informação recebida. Ocorreram muitas dificuldades para implementar este tipo de capacitação, principalmente devido à impossibilidade de encontrar housecleaners que se disponibilizassem por um período longo de tempo.

A solução encontrada foi adaptar o formato para o treinamento de apenas uma housecleaner, que se dispôs a trabalhar com o projeto e que felizmente já possuía experiência trabalhando com produtos naturais de limpeza, também conhecidos como "green cleaners". Como parte do treinamento, Dr. Jansen e a housecleaner elaboraram um curto treinamento em saúde e segurança no trabalho para housecleaners de duas horas de duração, a ministrar-se como seminário. A participação da housecleaner brasileira foi fundamental para o sucesso do treinamento, pois permitiu um maior entendimento dos problemas diários vivenciados pelas housecleaners em Massachusetts e o tornou mais prático e próximo das experiências diárias dos participantes. Entretanto, a dificuldade de formar grupos de housecleaners para participar dos seminários se manteve.

Os primeiros esforços do projeto visando recrutar housecleaners para os seminários se basearam na colaboração de algumas instituições locais que trabalham com brasileiros: BIC, LCHC, Brazilian American Association (BRAMAS) e Grupo Mulher Brasileira. Poucos brasileiros compareceram aos primeiros treinamentos realizados nestas instituições, o que tornou necessária a busca de novas formas de acesso à comunidade. Foi através de um trabalho conjunto com as igrejas brasileiras da região que este acesso se deu. Padres e pastores divulgaram os treinamentos em seus cultos e missas, além de ceder espaço em suas igrejas e templos para a realização dos seminários, onde os participantes se sentiam confortáveis. Através deste trabalho conjunto com igrejas o projeto treinou aproximadamente trezentas housecleaners em nove seminários realizados em oito cidades de Massachusetts: Boston, Cambridge, Lowell, Peabody, Acton, Somerville, Framingham e Quincy. A partir desta experiência positiva com as igrejas, o projeto aprofundou relações com alguns padres e pastores mais interessados em trabalhos comunitários, o que tem sido importante para a divulgação de todas as atividades do projeto.

O seminário incluiu uma apresentação em Power Point ${ }^{\circledR}$ e diversos materiais impressos. O primeiro se mostrou importante pelo impacto visual e o segundo permitiu que os trabalhadores levassem informações para casa (lista de produtos de limpeza não tóxicos, explicação sobre direitos trabalhistas, panfletos de instituições de apoio à imigrantes, etc).

No segundo ano do projeto o público alvo dos treinamentos tem sido os trabalhadores da construção civil, por ser este um dos setores que mais emprega brasileiros do sexo masculino em Massachusetts. Além disso, o setor encontra-se entre os que mais expõem os trabalhadores a riscos de lesões, doenças e acidentes no trabalho. Assim como na experiência com as housecleaners, a principal forma de acesso a essa população tem ocorrido através das igrejas. Inicialmente são feitas discussões com a comunidade sobre os perigos e riscos enfrentados por quem trabalha em diversos tipos de trabalho na construção civil. A partir daí são identificados grupos de trabalhadores mais homogêneos e agendados treinamentos específicos para cada área de atuação (pedreiros, pintores, carpinteiros, trabalhadores emtelhados, etc.).

Outra estratégia utilizada tem sido a identificação de pequenas empresas de construção de brasileiros, que através de um longo processo de treinamento e capacitação fornecido pelo Projeto Parceria, passariam a funcionar como empresaspiloto e se transformariam em modelos de trabalho seguro e saudável no setor. Nosso objetivo no caso da construção também é formar multiplicadores capacitados para disseminar os conhecimentos aprendidos nos seminários. Durante os treinamentos são utilizadas técnicas participativas de aprendizado, tais como atividades de grupo, demonstrações de materiais e equipamentos, simulações e projeção de vídeos e fotografias, permitindo um maior envolvimento dos trabalhadores. Também contamos com a presença de parceiros importantes como profissionais de saúde e segurança da Secretaria de Segurança e Saúde no Trabalho dos Estados Unidos (Occupational Safety and Health Administration ou OSHA) e representantes de firmas que vendem equipamentos de proteção para auxiliar na apresentação dos conteúdos práticos do treinamento.

No trabalho da construção civil foi imprescindível envolver no processo educativo as pequenas empresas e seus próprietários. Ao contrário do exemplo das housecleaners, em que os trabalhadores têm relativa autonomia para alterar o seu processo de trabalho, os trabalhadores da construção dependem do empregador ou patrão para melhorar as condições de saúde e segurança dos seus ambientes de 
trabalho. A principal dificuldade encontrada para a realização destes treinamentos é a falta de disponibilidade dos trabalhadores, que quase sempre trabalham em longas jornadas semanais. Uma das soluções encontradas para este problema foi aproveitar dias de neve ou chuva para realizar o treinamento.

\section{MÍDIA E ARTE COMO INSTRUMENTOS EDUCATIVOS}

O Projeto Parceria tem enfatizado o uso de recursos midiáticos e artísticos em suas atividades educativas, como ferramentas para veicular informações e facilitar o processo educativo da comunidade brasileira sobre saúde e segurança do trabalho. Esta é mais uma metodologia de trabalho que o projeto encontrou para que este assunto seja incorporado ao cotidiano da comunidade brasileira e que a preocupaçao com a prevenção faça parte do seu cotidiano. $\mathrm{Na}$ área de mídia e comunicação, veículos como jornal, rádio, televisão e internet vêm sendo utilizados.

Há cerca de dois anos a equipe do projeto escreve colunas semanais em jornais étnicos locais, como atualmente no jornal "A Notícia," abordando temas referentes à saúde e segurança no trabalho, atenção médica, seguro de saúde, imigração, atividades do projeto e outros variados tópicos de interesse da comunidade. O Projeto Parceria também tem sido referência para a imprensa americana local e de outros estados americanos, além de ser fonte de informações para jornais brasileiros, tais como a Folha de São Paulo, O Globo, e O Estado de São Paulo, quando estes jornais cobrem assuntos relacionados à população imigrante brasileira, suas condições de trabalho e problemas nos Estados Unidos.

Além da imprensa escrita, o projeto mantém um programa semanal de rádio em português, o "Radiola Brasil," que faz parte da programação da emissora de rádio da Universidade de Massachusetts Lowell, abrangendo uma área geográfica na qual residem cerca de 2.2 milhões de pessoas. O programa conta com a participação de convidados da comunidade brasileira e americana (profissionais de saúde, representantes de organizações governamentais e não-governamentais, padres, pastores, etc.) para esclarecer e divulgar assuntos de interesse comunitário, apresentando também música popular brasileira para os ouvintes. No momento os programas estão sendo gravados para que possam ser utilizados em outras rádios comunitárias, ampliando sua audiência e o alcance da informação oferecida.

A participação do projeto na televisão ainda encontra-se em fase de negociação. Até o momento houve participação da equipe em programas de entrevista conduzidos por jornalista brasileira em televisão a cabo local e entrevista para programa da TV Globo Internacional. No momento está em discussão a produção de programas específicos sobre o tema saúde no trabalho em TVs comunitárias e universitárias.

Recentemente, a página web do Projeto Parceria foi criada, apresentando informações sobre o projeto, dados gerais sobre a população imigrante brasileira, artigos, notícias, divulgação de eventos e links para outros portais importantes. Este site pode ser acessado no endereço www.cobwebproject.org.

Vale ressaltar que para obter resultados e ampliar o acesso à comunidade vem sendo necessário um trabalho de articulação com profissionais de área de comunicação, lideranças brasileiras e americanas, professores universitários e parcerias com organizações governamentais e nãogovernamentais.

Integrada ao componente midiático do projeto encontrase a utilização de elementos artísticos como ferramenta de aprendizagem. Para tanto, diversos métodos foram utilizadas, incluindo a educação popular de Paulo Freire (Freire, 1970). Um exemplo disso foi a criação de um grupo de teatro, chamado Ponto de Partida, que é aberto e gratuito para toda a comunidade brasileira, sem limitação de sexo ou idade. $\mathrm{O}$ grupo foi criado pela psicóloga e educadora Mariana Wagner, que fez parte da equipe do projeto e possuía experiência prévia no uso da arte para fins educativos. O processo criativo do grupo incluiu o uso de fotografias para identificação dos riscos enfrentados pelos brasileiros nos seus ambientes de trabalho (Photovoice). As fotos forneceram temas geradores para discussões sobre saúde e segurança no trabalho, com a participação de inspetores da OSHA. A partir da percepção do grupo sobre os riscos no trabalho foram selecionadas fotografias e elaborados textos referentes às mesmas, culminando com a confecção de um quilt (colcha de retalhos), elemento tradicional da cultura americana. Este quilt tem sido utilizado em outros eventos e atividades educativas do projeto como material auxiliar no processo de conscientização dos trabalhadores brasileiros.

O grupo Ponto de Partida elaborou também um roteiro para peça teatral, que inclui conteúdos de experiências reais vivenciadas por trabalhadores imigrantes brasileiros. Com base no roteiro da peça teatral um membro do grupo filmou o DVD "Sonho Meu, Realidade Nossa," que vem sendo apresentado para a comunidade como instrumento para gerar discussão e debate sobre a vida do imigrante brasileiro em Massachusetts. Cópias do DVD estão sendo distribuídas para líderes da comunidade brasileira e pesquisadores da justiça ambiental nos Estados Unidos. Este filme tem promovido um rico processo de troca de informações sobre migração e trabalho entre os imigrantes brasileiros. Todas estas formas alternativas e populares de disseminação de conhecimento e informação têm sido fundamentais para envolver a população brasileira local no trabalho do Projeto Parceria. Apesar de 
resultados muito positivos, não é fácil manter pessoas envolvidas por muito tempo. Com algumas exceções, a rotatividade dos participantes nas atividades artísticas é alta, o que dificulta a continuidade do trabalho. Temos, porém, muito claro que esta dinâmica faz parte do contexto da vida do imigrante.

\section{PARCERIAS}

O Projeto Parceria tem sido bem sucedido em ampliar as parcerias estabelecidas no início do projeto em 2003. Depois de um ano de trabalho em colaboração com uma inspetora do trabalho da OSHA, o Projeto Parceria foi fundamental para que esta organização firmasse uma "Aliança" oficial com o CIB. Esta Aliança, na verdade, faz parte da política do governo em buscar cooperação com organizações da sociedade civil para melhorar as condições de trabalho através de atividades voluntárias de treinamento e educação de trabalhadores e empresários. Independentemente da nossa dúvida sobre a eficácia desta política em mudar as condições de trabalho dos trabalhadores brasileiros, achamos que a parceria com a OSHA tem contribuído para que entendamos melhor os riscos enfrentados pelos trabalhadores brasileiros e para o treinamento de trabalhadores brasileiros sobre a legislação americana de saúde e segurança no trabalho.

O projeto também realizou uma nova parceria com o Programa de Vigilância Ocupacional da Secretaria de Saúde Pública de Massachusetts (DPH). Nesta colaboração, o Projeto Parceria possibilita a divulgação para o público americano e brasileiro de folhetos em português e inglês descrevendo as causas diretas de todos os trabalhadores que morreram por acidentes do trabalho nos últimos três anos. Além disto, esta parceria tornou possível aprofundar o trabalho de vigilância epidemiológica das fatalidades ocorridas, visando torná-las "sentinela" das condições de trabalho enfrentadas por imigrantes brasileiros, ou seja, que brasileiros e americanos aprendam sobre os riscos no trabalho enfrentados pelos imigrantes brasileiros ao informarem-se sobre as causas das mortes no trabalho.

Em nível de sociedade civil, o projeto colabora com outros projetos de pesquisa comunitária similares, dirigidos a outros grupos imigrantes como cabo-verdianos ou vietnamitas. A colaboração com estes projetos tem permitido a troca de experiências e a organização de atividades comuns para mudar leis ou influenciar órgãos do governo responsáveis pela pesquisa em saúde e segurança no trabalho, como o Instituto Nacional de Saúde e Segurança do Trabalho (NIOSH). Um importante parceiro do Projeto é o Grupo da Mulher Brasileira, uma organização não-governamental (ONG), organizada por mulheres imigrantes brasileiras em Boston. O Projeto Parceria tem colaborado com o Grupo para organizar uma cooperativa de limpeza residencial ecológica, que faz parte do projeto de justiça ambiental liderado pela Tufts University, de Medford, Massachusetts.

\section{CONSIDERAÇÕES FINAIS}

A migração de centenas de milhares de brasileiros para o Japão, Europa e Estados Unidos nas últimas duas décadas indica que uma significativa força de trabalho imigrante brasileira já se constituiu nestes países. Considerando que os brasileiros trabalham em situações perigosas e em trabalhos que os expõem a riscos de adoecer, lesionar-se ou até mesmo morrer, o tema de saúde e segurança no trabalho deve fazer parte das preocupações de todos os que se preocupam com o destino do imigrante brasileiro no exterior. Embora muitas vezes os próprios imigrantes só se preocupem com esta questão depois de haverem sofrido o mal-denominado "acidente do trabalho," cabe a todo profissional da área de saúde do trabalhador lutar para prevenir os incidentes.

O Projeto Parceria é a primeira experiência de que temos conhecimento de um projeto conduzido por pesquisadores brasileiros para estudar as condições de trabalho de imigrantes brasileiros no exterior. A experiência deste projeto deve servir de estímulo para que outros pesquisadores brasileiros incluam as questões de saúde e segurança no trabalho nas agendas de pesquisa dos órgãos brasileiros responsáveis pelo fomento à pesquisa em saúde pública. Muito ainda resta a fazer, mas baseado na nossa experiência com este Projeto nos últimos três anos, temos certeza que é possível melhorar as condições de saúde e segurança no trabalho do trabalhador brasileiro imigrante.

* Tiago Jansen e Andréa Barbosa são médicos especialistas em saúde do trabalhador pela UFBA $e$ doutorandos do Depto. de Ambiente do Trabalho da Universidade de Massachusetts Lowell.

** Carlos Eduardo Siqueira é médico sanitarista, professor assistente do Depto. de Saúde Comunitária e Sustentabilidade da Universidade de Massachusetts Lowell e Coordenador do Projeto Parceria.

\section{REFERÊNCIAS BIBLIOGRÁFICAS}

FAWCETT, S. et al.

(1996) "Empowering Community Health Initiatives Through Evaluation". In: Empowerment Evaluation: Knowledge and Tools for selfassessment and accountability. Thousand Oaks: California, Sage Publications.

FLEISCHER, Soraya Resende

(2002) Passando a América a Limpo: O Trabalho das Housecleaners Brasileiras em Boston, Massachusetts. São Paulo, Annablume.

FREIRE, Paulo

(1970) Pedagogia do oprimido. Rio de Janeiro, Paz e Terra. 